\title{
CORRELATION BETWEEN SMOKING STATUS, PERIODONTITIS AND SIGA LEVEL IN A SAMPLE OF PATIENTS
}

\author{
Radwa A Sallam* and Hazem Kazem*
}

\begin{abstract}
The present study was designed to investigate the correlation between periodontitis and smoking status and secretory IgA level among a sample of Egyptian patients. The study was carried out on male subjects with age ranging from $25-45$ years. The subjects were divided to 3 groups of 30 subjects each ; Group I (Control group) subjects with no clinical and/or radiographic manifestations of periodontal disease and no history of smoking, Group II which includes subjects diagnosed of periodontitis with no history of smoking and Group III which includes subjects diagnosed of periodontitis with history of smoking. The level of salivary immunoglobulin A (SIgA) was measured for the three groups. The results of this study reported significant decrease in the level salivary immunoglobulin A (SIgA ) in group III compared to group I and II $(\mathrm{P}<0.05)$
\end{abstract}

\section{INTRODUCTION}

Saliva plays an important role in maintaining oral and dental health. Secretary IgA contributes $60 \%$ of the total immunoglobulin count in the saliva. It is considered the first line of defense of the host against pathogens that colonize or invade mucosal surfaces and have been studied as potential diagnostic tests for periodontal disease. ${ }^{(1,2)}$

Periodontitis is one of the most highly prevalent chronic diseases worldwide. Periodontal disease, along with severe dental caries, causes tooth loss, which result in reduced functional capacity, selfesteem and social relationships. Hence, it affects people's quality of life .
Periodontitis is associated with several risk factors among which, is tobacco smoking. ${ }^{(3)}$ Throughout the years, studies has recorded delirious effect of smoking on periodontal tissues. However, there were different selected populations and /or different methodologies among these studies. In addition, the precise mechanism by which tobacco influences periodontal destruction and its related alteration still need complementary investigation ${ }^{(4,5,6)}$. It has been observed that smoking can alter salivary fluid, salivary enzymes. Yet, only a few studies has recorded the effect of tobacco smoking on salivary immunoglobulin $(7,8)$

\footnotetext{
* Lecturer of Dentistry, Health Radiation Research Department, National Centre for Radiation Research and Technology (NCRRT), Atomic Energy Authority, Cairo, Egypt.
} 
The aim of this study was to investigate the correlation between periodontitis and smoking status and secretory IgA level among a sample of Egyptian patients.

\section{SUBJECTS AND METHODS}

\section{Selection Criteria}

A total of Ninety male subjects of age range (25- 45) were enrolled in this study Subjects are apparently healthy and not suffering from any systemic diseases as evaluated by Cornell Index ${ }^{(9)}$ and by the modified Cornell medical index ${ }^{10)}$ A written consent was signed by all participants included in the study

\section{Exclusion Criteria}

Subjects were excluded if they had history of any systemic diseases, history of salivary gland surgery, chronic use of drugs that affect periodontal conditions history of alcohol intake and /or subjects who received professional hygiene or periodontal therapies in the 6 months preceding the screening

\section{Smoking status assessment}

Evaluation of Smoking habit was assessed by a self-reported questionnaire. Subjects were asked about the number of cigarettes they consume per day, the duration of smoking and the frequency of smoking. In addition, if they are aware of the link between smoking and gum diseases

\section{Periodontal analysis}

All subjects were clinically examined in a standardized manner. Examination instruments were adequately packed in sterilization bags and submitted to sterilization at National Center of Radiation Research and Technology (NCRRT) using cobalt -60 gamma source (GB50 Type B, Canada) at a dose of $25 \mathrm{KGy}$ for 6 hours under room temperature

Plaque index (PI), Gingival index. (GI), Probing depth (PD) and Clinical Attachment Level (CAL) measurements were recorded. ${ }^{(11-14)}$
Based on the clinical periodontal parameters, smoking status and selection criteria, subjects were divided into the three following groups:

\section{Group I: (Control group)}

Thirty subjects with no clinical and/or radiographic manifestations of periodontal disease and no history of any smoking

Group II: Thirty subjects diagnosed of periodontitis (a minimum of six periodontal pockets $\geq 5 \mathrm{~mm}$ or the loss of attachment of $\geq 3 \mathrm{~mm}$ ) with no history of smoking

Group III: Thirty subjects diagnosed of periodontitis with history of smoking I( 15 cigarettes / day for at least 5 years )

\section{Saliva sampling}

In this study, unstimulated whole saliva samples were used All saliva samples were obtained in the morning after an over-night fast. For the collection of saliva, the subject was seated in the coachman's position, head slightly down and was asked not to swallow or move his tongue or lips during the period of collection into gamma sterilized pre weighed plastic containers. Approximately $1 \mathrm{ml}$ of saliva was collected. The collected samples were centrifuged individually at $3000 \mathrm{rpm}$ for 10 minutes. The supernatant was removed and stored in small aliquots at $80^{\circ} \mathrm{C}$ until analysis

\section{Statistical analysis}

Data presented as mean and standard deviation (SD). Data explored for normality using Kolmogorov- Smirnov and Shapiro-Wilk tests. Data showed parametric distributions; One Way ANOVA used to compare between tested groups followed by Touky's post-hoc test.

The significance level was set at $\mathrm{P} \leq 0.05$.

Statistical analysis was performed with IBM ${ }^{\circledR}$ SPSS ${ }^{\circledR}$ (SPSS Inc., IBM Corporation, NY, USA) Statistics Version 24 for Windows. 


\section{RESULTS}

\section{Different between follow-up periods within tested parameters:}

Significant change for all tested parameters between time 1 and 2 for control group and test Group at $\mathrm{p} \leq 0.001$.

Table 1: Mean SD for different tested groups.

\begin{tabular}{|c|c|c|c|c|c|c|c|}
\hline & \multicolumn{6}{|c|}{ Group } & \multirow[t]{3}{*}{$\mathrm{p}$-value } \\
\hline & \multicolumn{2}{|c|}{$\begin{array}{l}\text { Group I } \\
\text { (Control) }\end{array}$} & \multicolumn{2}{|c|}{$\begin{array}{c}\text { Group II } \\
\text { (Periodontitis) }\end{array}$} & \multicolumn{2}{|c|}{$\begin{array}{c}\text { Group III } \\
\text { (Periodontitis+ Smokers) }\end{array}$} & \\
\hline & Mean & SD & Mean & SD & Mean & SD & \\
\hline Clinical attachment level (CAL) & $1.75^{\mathrm{c}}$ & 0.51 & $4.07^{\mathrm{b}}$ & 0.51 & $5.52^{\mathrm{a}}$ & 0.70 & $\leq 0.001 *$ \\
\hline Probing depth (PD) & $2.85^{\mathrm{c}}$ & 0.46 & $4.80^{\mathrm{b}}$ & 0.61 & $5.81^{\mathrm{a}}$ & 0.62 & $\leq 0.001 *$ \\
\hline Gingival Index (GI) & $0.80^{\mathrm{b}}$ & 0.76 & $3.00^{\mathrm{a}}$ & 0.80 & $3.30^{\mathrm{a}}$ & 0.82 & $\leq 0.001 *$ \\
\hline Plaque Index (PI) & $0.60^{\mathrm{b}}$ & 0.58 & $3.40^{\mathrm{a}}$ & 0.60 & $3.50^{\mathrm{a}}$ & 0.86 & $\leq 0.001 *$ \\
\hline $\begin{array}{l}\text { Secretory Immunoglobulin A } \\
\text { (SIgA) }\end{array}$ & $52.64^{\mathrm{a}}$ & 1.67 & $32.77^{\mathrm{b}}$ & 1.96 & $27.36^{\mathrm{c}}$ & 1.40 & $\leq 0.001 *$ \\
\hline
\end{tabular}

Means with Same Superscript letter within each row insignificant difference between tested groups. *= Significance

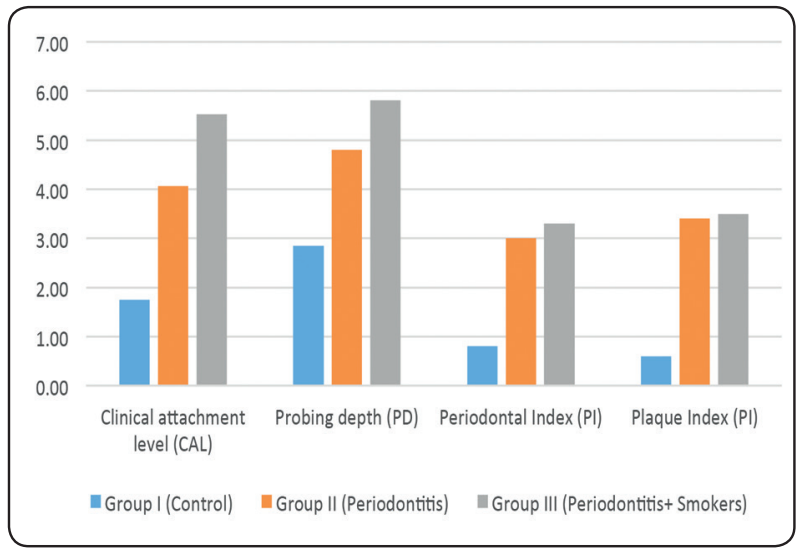

Fig. (1) Histogram showing mean clinical parameter values for the difference tested group

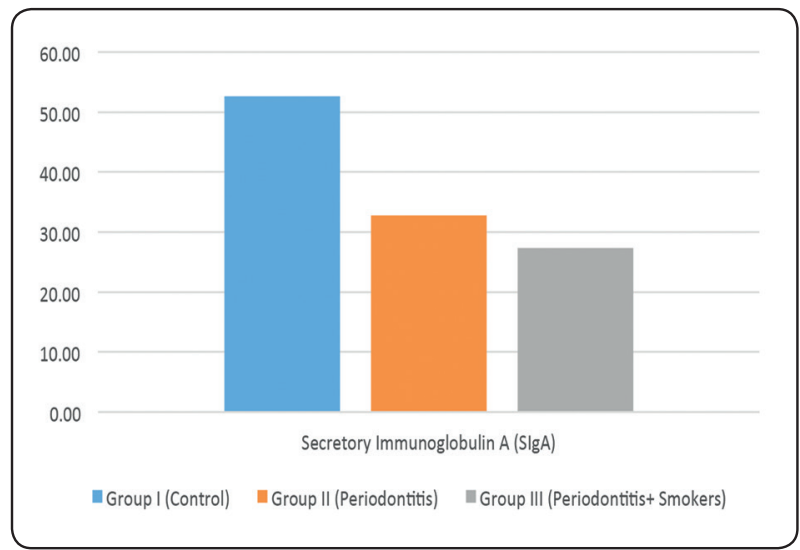

Fig. (2) Histogram showing mean Laboratory parameter values for the difference tested group

Saliva samples were collected from all subjects in both the study groups and the control group since it presents many advantages as a diagnostic tool. Saliva is easy to collect by a non-invasive technique, no special equipment is needed, and collection is associated with fewer compliance problems 
compared with blood collection.Furthermore, saliva is the first body fluid that comes into contact with the gaseous phase of cigarette smoking ${ }^{(18-20)}$

Evaluation of SIgA levels in particular was made since Secretory $\operatorname{IgA}$ is the primary immunoglobulin bathing mucosal surfaces and is the first line of defense. ${ }^{(21)}$

The present investigation resulted in significant decrease of SIgA levels among group III $p \leq 0.001$ (periodontal smoking patient compared to group II $\mathrm{p} \leq 0.001$ ( periodontal non smoking patients) and group I (control group) $\mathrm{p} \leq 0.001$. This was in was constituent with Rashkova et al 2010, Shilpashree et al 2012, Giuca et al 2014 and Chahal et al 2017 who highlighted a decrease in salivary IgA in cigarette smokers ${ }^{(20,22-24)}$

Decrease of SIgA could be as result of to the local effect of tobacco on the level of salivary immunoglobulin Furthermore, it could be attributed to the effect of Cigarette smoking on the immunoregulation of B-cell differentiation and its maturation . In addition, to the increased total T-cell numbers with a decrease in the $\mathrm{T}$ helper/suppressor cell ratio in heavy ${ }^{(6,22-24)}$

Comparing clinical parameters of periodontal disease between the groups of our study showed no significant increase of plague index among periodontal smoking patients compared to periodontal no smokers .This was in agreement with former studies. ${ }^{(6,25,26)}$ However, it was in contrast with former studies ${ }^{(27)}$ which showed higher plaque levels in smokers in addition to other studies which found less plaque levels in smokers .(28)

Regarding evaluation of gingival index. This study, recorded no significant differences in the inflammatory status between smokers and nonsmokers which is constituent with $(29,30)$ Contradictory, other studies ${ }^{(6,31)}$ found there was an decrease in gingival inflammation among smokers compared to no smokers

The non significant difference in plague and gingival indices could be attributed to the relatively small number of participants enrolled in our study

As for, Probing depth and Clinical Attachment Level, The present showed significant deeper pockets among periodontal smokers compared to periodontal nonsmokers and controls. This was similar to previous studies (6, 32-34) Additionally, increased attachment loss was observed which agreement with earlier studies ${ }^{(6,35,36)}$

\section{CONCLUSION}

Based on the results from the present study, it was proved that:

- Periodontal patients with Smoking habit had lower levels of salivary $\operatorname{IgA}$ compared to Periodontal patients with non-smoking habit and control group

- Estimation of the SIgA may serve as an indicator to assess the prognosis of periodontitis in smokers

- Smoking patients recorded higher plaque levels, probing depth, and loss of periodontal clinical attachment than what was found in non-smoking subjects.

- Regarding gingival inflammation, there was no significant difference between smoking periodontal patients, non-smoking patients and control

\section{RECOMMENDATIONS}

The data reported in this study high lights the delirious effect of smoking manifested in depletion of the level salivary immunoglobulin A . Smokers should be enrolled in programs for smoking cessation 


\section{REFERENCES}

1- Upadhyay, M; Eesha.; Goswam R; Malik. S and Vyas A (2017): Age and gender related changes in Salivary Immunoglobulin A in healthy subjects International journal of scientific research 6(4)343-344

2- Saloom H.F., Carpenter G.H. (2018) Saliva and Gingival Crevicular Fluid: Contributions to Mucosal Defense. In: Bergmeier L. (eds) Oral Mucosa in Health and Disease. Springer, Cham

3- Andrew W; Browar A W; Emily B. Koufos E B; Wei Y, Leavitt LL, Walter C. Prozialeck W C and Edwards JR (2018).Cadmium Exposure Disrupts Periodontal Bone in Experimental Animals: Implications for Periodontal Disease in Humans .Toxics.; 6(2): 32.

4- Kinane D F; Stathopoulo P G and Papapanou P N(2017). Periodontal diseases. Nature Reviews Disease Primers; 3 ( 17038):1-13

5- Wagenknecht D R; BalHaddad A A and Gregory R L. (2018). Effects of Nicotine on Oral microorganisms, Human Tissues, and the Interactions between Them Current Oral Health Reports;5 (1) : 78-87

6- Sreedevi M , Ramesh A , and Dwarakanath C (2012). Periodontal Status in Smokers and Nonsmokers: A Clinical, Microbiological, and Histopathological Study," International Journal of Dentistry : 10 pages

7- Koss M A., Castro C E., Gramajo A M., López M E(2016) sIgA, peroxidase and collagenase in saliva of smokers aggressive periodontal patients J Oral Biol Craniofac Res ; 6( 1): S24-S28

8- Golpasand Hagh L; Zakavi F; S Ansarifar S; O Ghasemzadeh O; Solgi G (2013).Association of dental caries and salivary sIgA with tobacco smoking Australian Dental Journal; 58: 219-223

9- Kerr, D.A. and Millard, H.D.(1965) Oral diagnosis.Mosby. Co.:77

10- Brightman,V.J.(1994). Rational procedure for diagnosisand medical risk assessment. Oral Medicine $9^{\text {th }} \mathrm{ed}$, Lippin Co .Philadelphia : 729-763

11- Sillness P and. Loe H (1964). "Periodontal disease in pregnancy II," Acta Odontologica Scandinavica, 22:121-135.

12- Loe H and Silness J (1963). Periodontal disease in pregnancy. I. Prevalence and severity Acta Odontol Scand, 21: 533-551
13- Newman M.G., Takei H.H.,. Klokkevold F.A (2003). Diagnosis, prognosis, and treatment plan Clinical Periodontology (9th ed.), Saunders, Philadelphia, PA: 441-447 citation

14- Salvi G.E.,. Lindhe J,. Lang N.P (2008) . Examination of patients with periodontal diseases Clinical Periodontology and Implant Dentistry (5th ed.), Blackwell Publishing Ltd, Victoria, Australia: 577-580

15- Macgregor, I. D. M (1984) "Toothbrushing efficiency in smokers and non-smokers," Journal of Clinical Periodontology, 11, (5) : 313-320 .

16-. Preber H and. Bergström J (1986) "Cigarette smoking in patients referred for periodontal treatment," Scandinavian Journal of Dental Research, 94, (2) : 102-108 .

17- Lie, M. A. van der G. A Weijden , Timmerman M. F, Loos B. G, van Steenbergen T. J. M, and an Der Velden, U. V (1986) "Oral microbiota in smokers and non-smokers in natural and experimentally-induced gingivitis," Journal of Clinical Periodontology 25, (8) : 677-686 .

18- Kaufman, E. and Lamster, I. B. (2000), Analysis of saliva for periodontal diagnosis. Journal of Clinical Periodontology, 27: 453-465.

19- Miricescu D; Greabu M;,Totan A, idilescu A and Rădulescu R (2011) . Therapeutics Pharmacology and Clinical Toxicology ; XV, (2) : 139-143

20- Giuca M; Pasini M; Tecco S; Giuca G and Marzo G . (2014) Levels of salivary immunoglobulins and periodontal evaluation in smoking patients Immunol.; 15: 5

21- Doifode, D. and Damle, S.G. (2011) . Comparison of salivary $\operatorname{IgA}$ levels in caries free and caries active children. Int. J. of Clinical Dental Science ; 2(1) : 10-13.

22- Rashkova MP, Toncheva AA. (2010) .Gingival disease and secretory immunoglobulin a in non- stimulated saliva in children. Folia Med (Plovdiv) ;52(4):48-55.

23- Shilpashree HS, Sarapur S. Evaluation of salivary immunoglobulin (2012) A levels in tobacco smokers and patients with recurrent aphthous ulcers. J Nat Sci Biol Med.;3(2):177-181

24- Chahal GS; Chhina K; Chhabra V ; Chahal A (2017). Smoking and its effect on periodontium Indian J Dent Sci;9 (1) ;44-51

25-. Calsina, G. Ramón, J.-M and. Echeverría J.-J, (2002) "Effects of smoking on periodontal tissues," Journal of Clinical Periodontology, 29 ( 8) : 771-776 
26-. Johannsen, A. Asberg M.. Soder, P.-O and. Soder, B(2005) "Anxiety, gingival inflammation and periodontal disease in non-smokers and smokers - an epidemiological study," Journal of Clinical Periodontology, vol. 32, (5) : 488-491 .

27-Bergstrom J and. Bostrom, L (2001) “Tobacco smoking and periodontal hemorrhagic responsiveness," Journal of Clinical Periodontology; 28 (7) : 680-685

28-. Machuca,. G , Rosales, I. Lacalle, J. R. Machuca, C and. Bullón P (2000) "Effect of cigarette smoking on periodontal status of healthy young adults," Journal of Periodontology; 71(1), pp. 73-7

29- Umeda, M.. Chen C,. Bakker,. I Contreras, A. Morrison, J. L and. Slots J (1998) "Risk Indicators for Harboring Periodontal Pathogens,” Journal of Periodontology; 69, (10), : $1111-1118$

30- Biddle J.,. Palmer, R. M. Wilson, R. F and Watts T. L. P. (2001) "Comparison of the validity of periodontal probing measurements in smokers and non-smokers," Journal of Clinical Periodontology 28 (8) : 806-812 .

31- Chen, X. Wolff, L.. Aeppli D. (2001) "Cigarette smoking, salivary/ gingival crevicular fluid cotinine and periodontal status. A 10-year longitudinal study," Journal of Clinical Periodontology, 28, (4) : 331-339.

32- Watts L. P (2001) "Comparison of the validity of periodontal probing measurements in smokers and non-smokers," Journal of Clinical Periodontology; 28, (8) : 806-812

33- Darby B,. Hodge, P. J, Riggio, M. P. and. Kinane, D. F (2000) "Microbial comparison of smoker and non-smoker adult and early-onset periodontitis patients by polymerase chain reaction," Journal of Clinical Periodontology; 27(6): $417-424$.

34. Bostrom. L Bergstrom, J. Dahlen G, and. Linder L. E (2001) "Smoking and subgingival microflora in periodontal disease," Journal of Clinical Periodontology; 28 (3): 212-219.

35-Calsina, G. Ramón J.-M, and Echeverría, J.J (2002)."Effects of smoking on periodontal tissues," Journal of Clinical Periodontology; 29, (8) : 771-776

36-Alexandridi F; Tsantila S; Pepelassi E (2018). Smoking cessation and response to periodontal treatment. Australian Dental Journal ; 63: 140-149 